\title{
FICCIÓN AUDIOVISUAL SERIALIZADA Y DEMOCRACIA: UN ESTUDIO EN LA TELEVISIÓN PÚBLICA EN MÉXICO
}

\section{SERIALIZED AUDIOVISUAL FICTION AND DEMOCRACY: A STUDY ON PUBLIC TELEVISION IN MEXICO}

\author{
Norma Pareja Sánchez \\ Universidad Autónoma de la Ciudad de México, México \\ (iD) http://orcid.org/0000-0003-2293-4552
}

Autor para correspondencia: Norma Pareja Sánchez, email: npareja02@yahoo.com.mx

\begin{abstract}
Resumen
Este trabajo aborda el papel que la ficción audiovisual serializada producida por la televisión pública en México tiene en la promoción de valores democráticos en el marco de la crisis de la democracia representativa y las actuales transformaciones sociotecnológicas en el sistema mediático. El objetivo es diagnosticar su estado para determinar las oportunidades que posee para la democracia, concibiéndolas como una política cultural. Se sigue una metodología cualitativa con enfoque documental-analítico que revisa la producción de ficción audiovisual serializada en la televisión pública mexicana mediante la elaboración de una base de datos. Ésta da cuenta de que Canal Once ha producido 96\% de las teleseries desde 1999, y es por tanto precursora en el tema. No se han encontrado razones estructurales de ello, pero sí probablemente institucionales al traducir el mandato como televisora pública de informar, educar y entretener con la operacionalización del concepto entretenimiento de calidad. Se concluye que existe un potencial cívico-educativo con el edu-entretenimiento en la producción nacional de ficción audiovisual como herramienta de intervención en la televisión pública en México dado su escaso aprovechamiento por los distintos sistemas públicos de televisión, su persistencia y predominancia histórica en el entretenimiento mediático y el disfrute que supone.
\end{abstract}

Palabras clave: democracia, ficción audiovisual, televisión pública, convergencia mediática, digitalización.

\begin{abstract}
This paper addresses the role that serialized audiovisual fiction produced by public television in Mexico has in the promotion of democratic values considering as a framework the crisis of representative democracy and the current socio-technological transformations in the media system. The objective is to diagnose its state in order to determine the opportunities it has for democracy, conceiving it as a cultural policy. A qualitative methodology with a documentary-analytical approach is followed to review the production of serialized audiovisual fiction of
\end{abstract}


public television in Mexico through the elaboration of a database. It is shown that Canal Once has produced $96 \%$ of the teleseries since 1999, which makes it a precursor in the matter. Structural reasons for this have not been found, but probably institutional ones by translating the mandate as public television to inform, educate and entertain with the operationalization of the concept of quality entertainment. It is concluded that there is a civiceducational potential from edutainment in the national production of audiovisual fiction as a tool for intervention in public television in Mexico given its scarce use by the different public television systems, its persistence and historical predominance in media entertainment as well as the enjoyment it implies.

Keywords: democracy, audiovisual fiction, public television, media convergence, digitization.

Recibido: 28/03/2021

Aceptado: 14/11/2021

\section{Introducción}

El abordaje del papel estratégico de los medios públicos en los distintos países es relevante dado el rol normativo que éstos invisten en una democracia: ser en esencia y operación instrumentos de los valores centrales de ella a partir del respeto a los derechos humanos, transparencia, diversidad, rendición de cuentas, libertad, pluralidad, igualdad y justicia; y desde una concepción ideal, dándole sentido como una forma de gobierno en la que prevalece la importancia a las opiniones de la ciudadanía para constituir el debate, la deliberación pública, la opinión pública, la libertad de expresión, la pluralidad de ideas, el acceso a la información y al conocimiento $\mathrm{y}$, por ende, al principio de igualdad (Sartori, 1993; Tocqueville, 1957; Touraine, 1995); y en ese tenor, propiciar un entorno mediático donde se observe pluralidad de contenidos, una amplia oferta televisiva, y el desarrollo de contenidos independientes para dar voz a distintos sectores de la sociedad (Valdés, 2013). En ese marco, la comunicación moderna es clave, y el servicio público aún más, pues su vocación es buscar la universalidad, misma que se vincula directamente con la configuración del "espíritu comunitario" que plantea Tocqueville (1957).

Aunque a lo largo de la historia los medios públicos han tenido que enfrentar severas y distintas presiones del poder político para corresponderse con las políticas acciones de estos, casos y experiencias emblemáticas, como la Broadcasting British Corporation (BBC), han demostrado que su función es imprescindible en las sociedades al mantener el interés público como fundamento de su operación ${ }^{\mathrm{i}}$, sobre todo, a partir de la independencia editorial, la autonomía de gestión y una sólida infraestructura que en conjunto contribuyan a extender la educación, la cultura y el conocimiento objetivo sobre la realidad desde la producción noticiosa y de contenidos. 
La UNESCO ha subrayado la centralidad de medios libres, independientes y plurales para la consolidación de la democracia, para tal fin, los distintos sistemas mediáticos deben contar con medios públicos, privados y comunitarios (Becerra \& Waisbord, 2015). En ese ámbito, es posible observar varios escenarios para los primeros: a) pueden diluir su esencia y convertirse en medios de Estado si responden exclusivamente a los intereses de éste y como parte de regímenes autoritarios, b) funcionar en un Estado formalmente democrático pero que los absorba y alinee a sus intereses, o bien, c) funcionar en un Estado formalmente democrático y lograr mantener su autonomía e independencia editorial a partir de una fuerte postura y/o coexistir con la actitud de Estado verdaderamente democrática.

En términos normativos, su papel democrático les exige ser promotores de los valores ya señalados, pero las circunstancias y el contexto sociopolítico en cada sociedad han resultado en condiciones contingentes para cumplir a cabalidad los presupuestos democráticos. Muchos de ellos, en radio, televisión o cinematografía han sido herramientas de propaganda de los gobiernos en turno. En el caso mexicano esto ha sido una situación persistente dada la estructura del sistema político que imperó por décadas desde el periodo posrevolucionario, así como una cultura política construida sobre la base de la subordinación al poder, las componendas o arreglos institucionales y una estructura burocrática orientada al beneficio de las cúpulas políticas y económicas.

La literatura académica producida respecto de este tema ha sido consistente en plantear las diversos aspectos y problemáticas derivadas de ello. Tanto en México como en América Latina se relacionan con la precariedad en las condiciones de operación debido al bajo presupuesto, la injerencia de los ejecutivos estatales y federales, la dificultad de mantener la autonomía de gestión y los esfuerzos aislados que algunos medios deben realizar para sortear estas adversidades y otros aspectos (Esteinou, 2008; Ortega, 2005, 2006; Pareja, 2009, 2011; Toussaint, 2009, 2011, 2017). En ese contexto, se identifican tres ámbitos problemáticos comunes en la región: los mecanismos de financiación, la estructura de control de la que dependen y el contenido que se programa (Becerra et al., 2012). Un rasgo más que comparten los medios públicos en el mundo es el potencial que tienen para aportar un mayor conocimiento ciudadano de asuntos políticos, sobre todo cuando tienen mayor preferencia (Holtz-Bacha \& Norris, 2001).

Todo ello en un escenario mundial en el que las últimas décadas han visto pasar una serie de transformaciones en los sistemas mediáticos derivados de la vinculación entre telemática y cibernética (Castells, 2009), de la convergencia de medios (Jenkins, 2008) y de la digitalización de la información; pero sobre todo cambios socioculturales procedentes del arribo de un nuevo tipo histórico de democracia, una democracia de escrutinio que desde mitad del siglo pasado se asocia con el subsecuente declive del modelo de democracia representativa (Keane, 2018). En ese marco, se han observado movimientos globales de vigilancia ciudadana y crítica a los diversos mecanismos de gobierno y con ello, la frustración e indignación con 
un creciente cuestionamiento al sistema de partidos, a los autoritarismos, a la corrupción, mismos que desprenden una amplia gama de movimientos sociales cuya agenda se configura en temas como la discriminación racial, la violencia contra las mujeres, el derecho al aborto, la diversidad sexual, el cambio climático, la globalización, los derechos humanos, entre los más destacados.

Tal densidad sociopolítica se ha observado paralela a cambios sustanciales en el paradigma comunicativo imperante hasta hace unos años: el esquema unidireccional y vertical de los medios masivos de comunicación que puede verse como la representación de la forma del poder en la modernidad. Con la digitalización tecnológica se hizo posible la interacción, multimedialidad y convergencia propias de la web 2.0, por ende, el modelo comunicativo actual se ha horizontalizado desplazándose hacia un uso dinámico y activo de la tecnología que entre otros fines ha potencializado cambios democráticos ${ }^{\mathrm{ii}}$, sumándose a lo que Keane (2018) llama la abundancia mediática, una nueva galaxia de medios de comunicación a partir de la cultura participativa, convergencia mediática y transmedialidad (Jenkins, 2008, 2009). Si bien John Keane (2018) no establece una relación entre las nuevas tecnologías de información y comunicación como elemento central de los cambios en la democracia como forma de gobierno, señala que se trata de un cambio histórico radical, "el nacimiento de una nueva clase de democracia posrepresentativa, caracterizada por el rápido crecimiento de muchas clases de mecanismos extraparlamentarios de escrutinio del poder" (p. 678), en donde claramente hay una participación ciudadana más activa, orientada al examen del desempeño público de diversos actores y ligada estrechamente al crecimiento de las sociedades saturadas por medios de comunicación múltiples, una nueva galaxia de medios de comunicación definida por el ethos de la abundancia comunicativa.

En el ámbito sociocultural, esos cambios se han ligado también a la configuración de procesos alternativos de comunicación constituyéndose en redes que cuestionan a las estructuras de poder en comunidades virtuales (Castells, 2009) y a través de consumos mediáticos, a partir de un uso específico de la tecnología en ese contexto determinado, asumiendo que ésta es una forma cultural (Williams, 1974).

No obstante, no puede obviarse que estos procesos desde la sociedad civil, "una esfera pública de la red" (Benkler en Van Dijck, 2016, p. 20), coexisten con un esquema de la industria global de medios definido desde hace décadas por la concentración de la propiedad y la derivación consecuente en conglomerados que delimitan la estructuración noticiosa, cultural y de entretenimiento, pues a la par de todos estos cambios, la industria audiovisual también se ha reconfigurado con nuevos agentes dominantes pero manteniendo esas tendencias de concentración; asimismo, en el panorama también se observa una mercantilización que ha expropiado la nueva esfera pública para salvaguardar las virtudes de la esfera corporativa, sobre todo a partir de la incautación de la privacidad (Van Dijck, 2016). 
La nueva ecología mediática ha implicado una extensión del consumo de medios a través de múltiples pantallas en oposición a la dominancia y verticalidad de la comunicación de masas que tenía en la televisión el mecanismo concentrador de la representación de la escena mundial, que pese a los cambios mantiene su central importancia en la vida cotidiana que se identificó hace décadas (Morley, 1986; Orozco, 2014; Silverstone, 1996). En esa lógica de multipantallas, alta selectividad e incluso saturación que implica la vasta diversidad de medios y contenidos, la ficción televisiva sobre todo con series y telenovelas, se ha mantenido y recién alcanzado un importante auge en virtud de su rol como proveedor de entretenimiento, con lo festivo y melodramático (Dorcé, 2020; Martín-Barbero, 1987) y del lugar que ya tenía desde hace varias décadas en comparación con la información y la cultura, los otros dos macrogéneros que dominan el panorama en la dieta mediática.

En atención a ello, este trabajo aborda el papel que la ficción audiovisual serializada y producida por la televisión pública en México tiene en la promoción de valores democráticos. El texto describe inicialmente las coordenadas teóricas que hipotéticamente dan forma al objeto de estudio con los conceptos de política cultural, eduentretenimiento y el disfrute mediático; enmarca la evolución sociotecnológica del sistema de medios en la crisis de la democracia representativa con la pervivencia del melodrama y la maduración de la ficción audiovisual serializada. Se diagnostica la producción de esta en la Tv pública en su dimensión histórica, educativa y lúdico-estética con el fin de determinar las oportunidades que posee para tal fin. Éstas se conciben como parte de una política cultural que fortalezca la industria nacional al tiempo que articule la defensa del patrimonio nacional, el acceso de sectores populares a la cultura, mitigue la desigualdad social en la apropiación del arte e impulse medidas de protección y visibilización a las culturas locales; y sobretodo, interpe a la audiencia desde sus propias matrices culturales y gustos. Se apuesta asimismo, por la búsqueda de posibilidades que en específico la televisión pública tiene para alimentar la diversidad cultural fuertemente limitada por los flujos comunicativos sobre todo norteamericanos (McBride, 1980; Mattelart, 1995) durante las décadas pasadas, los cuales parecen prevalecer. Finalmente, a partir de un diagnóstico de la producción audiovisual serializada en la televisión pública en México, se establece el potencial cívicoeducativo que tiene la ficción audiovisual, empleándola como herramienta de intervención como se ha hecho en la BBC desde hace casi cien años y más recientemente en Argentina; pues prácticamente ninguna televisora pública nacional ha trabajado esa veta.

\section{Coordenadas teóricas: La triada de políticas culturales, edu-entretenimiento y el disfrute mediático}

En este apartado se revisan tres conceptos, los cuales en conjunto pueden aportar claves para la comprensión y el abordaje del papel de la ficción 
audiovisual serializada respecto de la promoción de valores democráticos en televisión pública a partir de constituirse como una política cultural en clave de edu-entretenimiento, éste como mecanismo de mayor vinculación con las audiencias a partir del disfrute mediático, de modo que la relación comunicativa entre contenido y público sea mucho más estrecha.

\section{a) Políticas culturales}

Hacia finales de la década de los ochenta Néstor García Canclini (1987) planteaba la necesidad de conformar el campo de estudio sobre la acción política respecto de la cultura, lo que más tarde sería el de las políticas culturales. Ello implicó la necesidad de analizar la importancia de la definición de estrategias de desarrollo cultural conscientes de sus objetivos finales y del modo en que debían articularse la educación, la composición sociocultural de la población y el desenvolvimiento económico. De modo que la cultura dejara su esencialismo folcklorista y pudiera ser entendida como "el conjunto de procesos donde se elabora la significación de las estructuras sociales, se la reproduce y transforma mediante operaciones simbólicas, y es posible verla como parte de la socialización de las clases y grupos en la formación de las concepciones políticas y en el estilo que la sociedad adopta en diferentes líneas de desarrollo" (García Canclini, 1987, p. 25); se sentaban así las bases para comprender la necesidad de que el desarrollo cultural fuese tomado como una política pública y con ello el involucramiento y rol del Estado en el proceso de democratización fomentando la expresión y el avance de los sectores populares con el reconocimiento de los derechos culturales.

En ese marco, los medios de comunicación juegan un papel relevante pues según MartínBarbero (1987) a la vez que objetos de políticas, la comunicación y la cultura constituyen hoy un campo primordial de batalla política al ser vistas como el escenario estratégico que le exige a la política recuperar su dimensión simbólica -su capacidad de representar el vínculo entre los ciudadanos, el sentimiento de pertenencia a una comunidad- para enfrentar la erosión del orden colectivo.

Pese a que ya han pasado al menos tres décadas desde esta definición, puede seguirse a García Canclini (1987) pues nos parece que tiene vigencia y aplicabilidad, de modo que entenderemos por políticas culturales al "conjunto de intervenciones realizadas por el Estado, las instituciones civiles y los grupos comunitarios organizados a fin de orientar el desarrollo simbólico, satisfacer las necesidades culturales de la población y obtener consenso para un tipo de orden o de transformación social” (p. 26).

En su análisis plantea varios paradigmas políticos sobre la acción cultural, dos nos resultan pertinentes al enfocarse en reconocer a la cultura como parte de una expresión social amplia y su enlace con la democracia en el sentido del reconocimiento de la diversidad cultural (García Canclini, 1987):

1) La democratización cultural: es un programa de distribución y popularización del arte, el conocimiento científico y las demás formas 
de "alta cultura". Su hipótesis básica es que una mejor difusión corregirá las desigualdades en el acceso a los bienes simbólicos

2) El paradigma de democracia participativa: se defiende la coexistencia de múltiples culturas en una misma sociedad, propicia el desarrollo autónomo y relaciones igualitarias de participación de cada individuo en cada cultura y de cada cultura respecto de las demás.

$\mathrm{Si}$ relacionamos la política cultural con las actividades de la televisión pública es posible identificar que la función de esta opera desde la democratización cultural, al acercar las expresiones artísticas a la población como el modelo de Canal 22, y con el paradigma de democracia participativa, con la inclusión y visibilización de las distintas expresiones culturales de distintos grupos sociales en México, así como con la promoción a través de diversos programas de participación ciudadana.

La UNESCO (2006) ha establecido que la televisión pública se rige bajo cuatro principios: 1) la universalidad (alcance a todos los ciudadanos), 2) la diversidad en géneros y programas, audiencias y temas, 3) la independencia de la difusión comercial y la influencia política, y 4) la diferenciación marcada por la innovación y liderazgo. Sin embargo, en México existe una definición ambigua de hacer servicio público en medios de comunicación (Ortega, 2005), pues hay una influencia política clara de distintos actores en el ejercicio de los medios públicos con escasa independencia que propicia una fuerte tensión entre el ser (realidad en la operación) y el deber ser (ideal o normativo) ${ }^{\text {iii. Tienen también }}$ un apremio estético que surge de un interés político, de un objetivo que apunta al uso social y educativo de una tecnología, al servicio público con un alcance masivo y en América Latina, por lo menos su historia ha estado ligada al Estado (Toussaint, 2011, 2017).

En la preminencia de la cultura de masas, el entretenimiento es una constante en el consumo mediático, se ha convertido en un género que resulta polémico en su implementación en los medios públicos dada la tradición de alta cultura, pero que al mismo tiempo es importante para vincularse con la audiencia. García Canclini (1987) apuntaba que el descubrimiento de las funciones políticas de la cultura no puede desentenderse de su sentido estético o simplemente recreativo y al ser la cultura un territorio donde los grupos sociales realizan compensatoriamente sus deseos, no necesariamente hay utilidad práctica, y sí un goce estético y el enriquecimiento de la comunicación, no producen réditos y significan placer y experiencia.

Una buena política cultural no es la que asume en forma exclusiva la organización del desarrollo cultural en relación con las necesidades utilitarias de las mayorías sino que abarca también condiciones de juego y experimentación. La política cultural debe ser también una política del placer (p. 5152).

Ello sugiere una evolución del concepto clásico de televisión pública y la ruptura del modelo de televisión de alta cultura donde prevalece la difusión 
de las bellas artes como estrategia pedagógica para aculturar a las masas sin contemplar la dimensión lúdica. Por lo que se buscaría captar a un número mayor de televidentes al tiempo que se construye ciudadanía, además de romper con la perspectiva crítica sobre la función de entretenimiento en una visión monolítica como lo ha señalado Orozco (2005). En tal sentido, se considera sustancial la noción de edu-entretenimiento que es un género híbrido innovador y pertinente en este marco de análisis.

\section{b) El edu-entretenimiento (EE)}

El EE se define como "el proceso de diseñar e implementar una forma mediada de comunicación con el potencial de entretener y educar a las personas, con el objetivo de mejorar y facilitar las diferentes etapas del cambio pro-social (de comportamiento)" (Bouman, 1999, p. 25). Su pertinencia en términos educativos es amplia sobre todo porque al implementar claves de entretenimiento interpela a las audiencias mediante lo festivo, lúdico y divertido, que finalmente forman parte de la nueva epistemología mediática y cultural (Postman, 2012). Se trata del uso de educación no formal a través de la comunicación masiva como parte de algunas estrategias educativas.

Se trata de la necesidad de moverse más allá de la información hacia la comunicación, más allá del logos y del mito, esto es: Más allá de la razón, hacia la emoción, no dualmente, sino en estrategias integradas en las que la educación no es sólo la transmisión de la información sino la acción de involucrar a las personas en el cambio de la sociedad (Tufte, 2004, p. 39).

El papel del entretenimiento se ha consolidado como el marco en el que se desenvuelven diversos géneros $\mathrm{y}$ formatos sobre todo en televisión y desde la configuración de la cultura de masas, la ficción audiovisual se coloca claramente en él. Éste es un macrogénero en el que se integra el melodrama moderno y premoderno, que rescata la esencia de la fiesta, práctica cultural que renueva el sentido de la cotidianeidad (Martín-Barbero, 1987). Para Zillman (en Igartúa \& Muñiz, 2008) el entretenimiento mediático posee un valor clave para propósitos educativos.

En ese contexto, los géneros pueden ser vistos como matrices culturales, universales y populares con un amplio potencial de innovación y creatividad para la televisión pública, son maleables y se transforman, su forma de operar es entre lo conocido y lo innovador y por ello es difícil encontrarlos en su estado puro (Mazzioti, 2001), así que se puede considerar fructífera la vinculación entre el entretenimiento y la educación, ésta más propia de los medios públicos.

Para Mazzioti (2001), hay al menos tres postulados generales amplios e interrelacionados sobre los que se instalan los discursos en una televisión pública dirigida a la construcción de ciudadanía mediante diversos géneros: necesita asentarse en una programación de calidad, hacerse cargo de lo que deja vacante la televisión comercial, 
sin pensar sobre la base de géneros con una intencionalidad educativa o concientizadora $y$ necesita tener en cuenta la diversidad cultural, la tolerancia y la apertura hacia otros sujetos culturales. Considera muy útil la implementación del género de ficción tanto con telenovelas como teleseries, las primeras mucho más arraigadas en las culturas latinas y las segundas derivadas de la tradición anglosajona con las historias por entregas y las series norteamericanas por sus objetivos de relajación y entretenimiento vinculadas con contenidos concientizadores y educativos pues habla de mundos posibles que enriquecen la vida del espectador.

El EE ha sido útil sobre todo para hacer frente a diversos retos sociales o sanitarios (MoyerGusé, en Igartúa \& Vega, 2014; Tufte, 2004). En América Latina, el entretenimiento educativo surge asociado al llamado mercadeo social que es la primera generación. Tufte (2004) habla de que éste si bien no nació en la televisión pública, se desarrolló en los años setenta y se enfocó rápidamente en géneros de ficción, particularmente relacionados con los medios masivos. Uno de los pioneros en el uso de ficción televisiva para el cambio de comportamiento pro-social fue el mexicano Miguel Sabido. Entre 1975 y 1985, Sabido produjo un total de siete telenovelas con mensajes de carácter educativo. Estas fueron transmitidas por la cadena televisiva más grande de México -Televisa- y tuvieron una gran audiencia.

Un caso emblemático en el que se empleó el EE y en el que además participó la televisión pública fue el de la telenovela Mucho corazón producida por el Sistema Chiapaneco de Radio, Televisión y
Cinematografía en conjunto con PCI Media Impact y el Banco Mundial en 2012, y cuya historia entrelaza la vida de Maruch, una joven indígena de una comunidad rural de Chiapas y la necesidad de hacer un presupuesto, ahorrar, invertir y evitar los abusos financieros (Banco Mundial, 2014) ${ }^{\mathrm{iv}}$.

Para el caso latinoamericano, se habla incluso de ejemplos en los que el EE en telenovelas han tenido un importante labor educativa en torno a problemáticas sociales pues el proceso de intervención educativa pasa desapercibido o se mezcla con la historia que se desarrolla en contextos cercanos a la cotidianeidad del espectador, incluso también en casos como India, donde la integración de la televisión en ciertas zonas se correlacionó con menores índices de natalidad en comparación con otras regiones del mismo país que tenían menor acceso, en virtud de los contenidos de las historias televisivas (BBC, 2013).

Según un estudio realizado por el Banco Interamericano de Desarrollo, de acuerdo con datos censales en el periodo 1970-1991, las mujeres que vivían en áreas cubiertas por la señal Rede Globo - la red que tiene un monopolio efectivo en la producción de telenovelas en Brasil - bajaron significativamente su fecundidad, pues las telenovelas brasileñas comenzaron a retratar familias que eran más pequeñas que el promedio nacional, y en consonancia la tasa de fertilidad cayó en las regiones donde estos programas se emitían mientras las mujeres que miraban las telenovelas buscaban emular a los personajes en la pantalla. El impacto de la presencia de Globo fue más fuerte para las mujeres 
de edad cercana a la protagonista de la telenovela (Leanza \& Zafarroni, 2017) $)^{\mathrm{v}}$.

Tufte (2004) señala que el EE se ha utilizado cada vez más en el tratamiento de temas relacionados con la salud (presión arterial, consumo de tabaco, promoción de vacunaciones, planificación familiar y la prevención de VIH/SIDA), con cada vez más productos de medios, especialmente de radio y telenovelas y una serie similar de productos diseñados para educar a las audiencias involucrándola en un enfoque de salud.

\section{c) El disfrute mediático}

El tercer elemento que hipotéticamente explica y ayuda a explorar el objeto de estudio es el del disfrute mediático (media enjoyment), que se define bajo una perspectiva psicologista y de los efectos persuasivos de la ficción audiovisual en las audiencias, por ende, tiene un carácter individual o grupal a diferencia de los anteriores, cuya esencia es colectiva, pero sobre todo cultural. Si bien esto puede resultar poco ortodoxo desde el punto de vista académico dadas las diferencias epistemológicas, la pertinencia en tal sentido es la dualidad que nos define como seres humanos, construidos social y culturalmente, pero al mismo tiempo con una dimensión individual; la articulación de ambos aspectos resulta útil para explicar la relación medios-audiencias, sobre todo si consideramos que la realidad está objetiva y subjetivamente construida ${ }^{\mathrm{vi}}$.

Desde el punto de vista académico puede hablarse de la necesidad de promover valores así como políticas culturales y de comunicación que contribuyan a la democracia y por ende al cambio social. No obstante, es necesario considerar las propias necesidades particulares, las emociones y los elementos que hacen establecer una relación con determinado producto cultural y contenido mediático, de modo que lo que se concibe formalmente necesario sea al mismo tiempo aquello que resulte de interés, gusto y propicie afectividad en la audiencia. La ficción audiovisual puede apelar a la memoria autobiográfica, esto es, a los recuerdos personales sobre la propia vida. Este proceso cognitivo recibe el nombre de resonancia personal y depende del grado de implicación con el relato (Zillman en Ortiz, 2018).

La noción de disfrute mediático ha sido ampliamente observada por la investigación de los efectos; es vista como relevante en la investigación en comunicación dado que Zillman (en Igartúa \& Muñiz, 2008) ha dicho que en el futuro de la investigación la concerniente al entretenimiento mediático estará entre los primers temas pues "la sociedad actual vive en la era del entretenimiento" (p. 26). Este concepto asocia experiencias mediáticas con el placer, considerando que la mayoría de ellas en el entretenimiento son complejas, dinámicas y con múltiples facetas fundamentalmente desde el punto de vista cognitivo, emocional y fisiológico (Vorderer, Klimmt \& Ritterfeld en Ortiz, 2018). Se enfoca concretamente al consumo mediático de la ficción estableciendo que éste tiene como objetivo el alcance de un estado emocional placentero (Ortiz, 2018) y es balanceado de manera positiva, o sea asociado con experiencias emocionales positivas (Igartúa \& Muñiz, 2008). No obstante, su 
investigación es compleja porque su definición es ambigua y entraña aparentes contradicciones como el placer vinculado al sufrimiento en el drama o a la ansiedad en el terror y/o violencia (Barthes, 2018; Igartúa \& Muñiz, 2008; Ortiz, 2018). Para Vorderer (2003) hay dos tipos de recepción de la ficción audiovisual:

1) Un modo analítico y distante: supone cierto desapego del relato, de manera que el espectador no se siente implicado con los personajes y la trama, sino que, más bien, reflexiona sobre la forma de presentación.

2) Un modo de recepción afectiva y cognitiva de alta implicación: supone vivir el relato desde dentro, lo que significa que el sujeto se deja llevar por la historia y los personajes. Ambos modos de recepción suelen estar correlacionados y oscilan a lo largo de un visionado.

Ortiz (2018) señala que existen cinco requisitos para el disfrute mediático: “1) la suspensión de la incredulidad, 2) empatía con el personaje, 3) deseo de interacción con el personaje (mental o real), relación parasocial, 4) sensación de estar ahí y 5) interés en el tema, problema o ámbito abordado" (p. 91-92).

Dentro de la investigación académica se ha analizado al disfrute mediático como proceso placentero frente a contenidos audiovisuales de entretenimiento con el género de la ficción (Barthes, 2018; Igartúa \& Muñiz, 2008; Ortiz, 2018;). Ortiz (2018) señala que existen tres resultados y consecuencias del entretenimiento: a) Transferencia emocional: sentir alivio; b) Catarsis: efecto de purga y purificación y c) Aprendizaje: relación entre entretenimiento, comprensión y aprendizaje. Este último es que más se asocia a los géneros híbridos como el infotainment y edutainment.

Por su parte, Igartúa \& Muñiz (2008) e Igartúa (2008) han señalado que los procesos de recepción como la inducción afectiva, la identificación con los personajes, la resonancia personal y la cercanía cultural juegan un papel central para explicar el disfrute ocasionado por la ficción y, citando a Zillman, apuntan que el estudio de la afectividad es clave para entender los efectos de los medios de comunicación.

En el siguiente apartado se revisan de manera sucinta las transformaciones tecnológicas que se han experimentado en el mundo para comprender el escenario en que operan los medios de comunicación y su nueva configuración. Asimismo con ello como telón de fondo se la preminencia en el entretenimiento mediático de la ficción audiovisual y su capacidad de adaptación en distintos momentos de cambio tecnológico.

\section{Revolución tecnológica, melodrama y ficción audiovisual}

Como se ha mencionado antes, en las últimas décadas se han experimentado importantes cambios a escala global que en la articulación tecnología, sociopolítica y economía, han propiciado nuevas prácticas culturales bajo constantes, dinámicos y activos procesos de interacción social deslocalizada (Morley, 2009). Sin embargo, es imprescindible mencionar que la brecha digital deja en la exclusión 
de esta dinámica a millones de personas en el mundo, sobre todo en América Latina. En México, alrededor de 30 millones de personas no son usuarios de internet (INEGI, 2020) y por ende, existe una conectividad limitada ${ }^{\text {vii. }}$.

Sin obviar lo anterior, pero enfocándonos en la tendencia global del cambio de paradigma comunicativo, hay que señalar que el potencial tecnológico de la web 2.0 basado en la digitalización, convergencia y multimedialidad ha derivado en lo que Jenkins $(2008,2009)$ llama la cultura de la convergencia, compuesta por la inteligencia colectiva, la cultura participativa y la transmedialidad. Castells (2009) dice que el internet permite una diversidad de formas culturales alternativas en la red, donde la bidireccionalidad o cambio de roles entre emisor y receptor y la posibilidad de difundir prácticas derivadas de la recepción de mensajes es posible desde la autocomunicación e hiperactividad (Scolari, 2008) al tiempo que se transforman las estructuras de conocimiento y poder (Castells, 2009; Jenkins, 2008, 2009;).

Para Scolari (2008), el rol activo de la audiencia queda claro a partir de la reticularidad, (configuración de muchos a muchos), la hipertextualidad (usuarios comparten textos entre sí así como enlaces compartidos por varias personas), así como por la multimedialidad (convergencia de medios y lenguajes), y sobre todo se da en el marco de la cultura. La predominancia narrativa de los medios analógicos masivos durante el siglo XX cedió terreno a las nuevas narrativas social media que comparten roles discursivos con los prosumidores mediáticos, los tradicionales, las redes sociales y los medios web (Karbaum, 2018). El espectador, ahora consumiendo en abundancia series televisivas (binge watching), ha transitado del monomedio al metamedio (Scolari, 2008), ya que el consumo se desarrolla en múltiples pantallas.

En ese contexto, la narrativa melodramática serializada lejos de extinguirse se ha adaptado entre los diversos momentos y transformaciones tecnológicas en la historia de la humanidad quizá como la producción cultural más fuerte en ese sentido. Puede situarse su origen desde la invención de la imprenta con la literatura de cordel y el colportage, luego en la serialidad con los folletines o novelas por entregas del siglo XIX, posteriormente en la producción concreta de narrativas en la comunicación de masas como el cine (seriales en el cine mudo), radioteatro y más tarde en la televisión con las soap operas, teleseries y telenovelas latinoamericanas (principalmente colombianas, mexicanas y brasileñas) (La Pastina, Rego \& Straubhaar, 2004); desde el oriente a principios de siglo XX en el manga y el ánime. Asimismo, ha prevalecido desde la producción serial de calidad en la tv de cable con $\mathrm{HBO}$ y la BBC, y más recientemente en la producción y transmisión por y para internet, el streaming con la multiplicidad de proveedores en diversos medios y pantallas. De modo que el melodrama en los últimos años se ha reubicado como modalidad constitutiva de la experiencia moderna y modo dominante en la afectividad contemporánea global (Dorcé, 2020).

El melodrama se integra como elemento central de la narrativa pasada y presente. En la 
actualidad se articula con la ficción televisiva expandida en múltiples pantallas, a partir de la fuerza del relato, las intrahistorias, la realidad sociopolítica y la repetición (Carrión, 2015) que la serialidad desde los folletines le otorga. La narrativa serial facilita una vinculación afectiva con la audiencia y en televisión desde la posguerra comienza un proceso de maduración que a finales de la década de los noventa $\mathrm{y}$ principios de siglo XXI repunta con un auge importante, como señala Cascajosa (2009), a partir de un éxito masivo entre el público, con contenidos provocadores y apuestas narrativas renovadoras. La llegada del internet y con ello proveedores de contenidos en streaming como Netflix supuso un empuje mucho mayor sobre todo con una recomposición del mercado audiovisual ${ }^{\text {viii }}$.

Asimismo, se puede hacer una clasificación general de las transformaciones globales que ha tenido la ficción televisiva mostrando su fortaleza como género narrativo a pesar de los diversos cambios tecnológicos que ha experimentado durante siglos. Identificamos tres momentos ${ }^{\mathrm{ix}}$ centrales en su proceso de maduración los cuales se han dado de manera paralela a importantes transformaciones socioculturales, como los cambios en el consumo cultural ${ }^{\mathrm{x}}$ :

1) El primero de surgimiento (1928-1945), consigna desde las series inaugurales de televisión a nivel experimental entre la televisión mecánica y la eléctrica, la llamada pretelevisión, así como la ficcionalización a partir de adaptaciones de teatro y radio, se ubica hasta el fin de la Segunda Guerra Mundial que ralentizó su avance.
2) El segundo momento de expansiónglobalización (1946-2006) inicia con la posguerra, en él puede observarse un proceso de maduración claro de la ficción tanto en su producción sobre todo inglesa $\mathrm{y}$ norteamericana con teleseries, oriental con el vínculo manga-ánime, e iberoamericana con telenovelas; como en la distribución que constituye el desarrollo del mercado y el consumo pues ya se convierte en un fenómeno cultural global y se consolida a la par que la televisión masifica su presencia en los hogares en el mundo y la ficción ocupa una parte importante de las parrillas programáticas en el orbe.

3) El tercer momento de extensióndesplazamiento a multipantallas (2007 a la fecha), da cuenta de la expansión de la ficción audiovisual que transita de la televisión a múltiples pantallas, derivado del desarrollo de la web 2.0 en 2004 que es ya interactiva (de manera personalizada de un sujeto a otro u otros y con mayor diversidad de temas). Se caracteriza también por la convergencia mediática y la digitalización, se acentúa la globalización de la industria audiovisual al lograr el acceso a la producción de diversas latitudes antes invisibilizadas como las nórdicas, de los Países bajos, alemanas, francesas, españolas, turcas, orientales (japonesas y coreanas). Se establece este periodo fundamentalmente a partir de la entrada de Netflix ${ }^{\mathrm{xi}}$ al mercado global del streaming en 2007 que transformó 
la industria, logró una predominancia en el mercado audiovisual a partir de: a) distribución de series y películas de las grandes productoras norteamericanas y b) producción original o financiamiento a productoras independientes en $2013^{\mathrm{xii}}$.

México no ha sido ajeno a este cúmulo de procesos que son una tendencia mundial pese a las limitaciones de conectividad que entraña la brecha digital, pues la oferta de streaming en 2020 creció 35 \% con respecto a 2019 (López, 2021). A fin de ampliar la discusión sobre el papel ideal que la televisión pública debe tener respecto de la democratización de la sociedad en este panorama, se hace necesario hacer un diagnóstico para identificar las oportunidades que tiene con la producción y difusión de la ficción serializada en México.

\section{Diagnóstico de la producción de ficción audiovisual televisiva de carácter público en} México

En la óptica de la globalización de los procesos sobre todo de la televisión como depositaria y centro de los cambios tecnológicos y socioculturales, se observan dos experiencias interesantes en este tenor: el de Reino Unido con la BBC que logró desde hace varias décadas adaptarse a la dinámica global del mercado de contenidos audiovisuales y destacar en ese ámbito; asimismo sobresale el caso de Argentina en América Latina que incluyó en los últimos años de manera abierta a la ficción audiovisual como una política de comunicación, en ese país se apeló a la democratización de la ficción audiovisual a través de la resignificación de la televisión pública (Pía Nicolosi, 2013). Ambos casos se reseñan muy brevemente sólo con el objetivo de identificar referentes de comparación en el mismo tema que el presente trabajo sin un afán de exhaustividad que desafíe los límites espaciales posibles. La profundización sobre la presencia y expansión de políticas públicas para fomentar la producción de audiovisuales televisivos en Argentina, así como en otros países de la región en el marco de las transiciones a la democracia es vital para ampliar la discusión; no obstante, esto ya no puede ser abordado en este artículo.

El primero es altamente conocido. Tiene en su registro el haber producido la primera serie desde un sistema público de radiodifusión hace casi un siglo, The man with de flower in his mouth (1930, BBC). Asimismo, se destaca la serie Los Archer (1951), desarrollada con el Ministerio de Agricultura, la cual se empezó a transmitir desde 1951 y se mantuvo al aire cada domingo. En los primeros 22 años, éste era un producto de EE que comunicaba contenido educativo a los agricultores de Inglaterra. A mediados de los cincuenta, la audiencia de Los Archer la componía dos de cada tres adultos ingleses y todavía continúa siendo muy popular (Tufte, 2004). En adelante, la BBC produce con prestigio de calidad para la mancomunidad y despliega sus títulos por diversos canales por cable, satélite e internet en un mercado global. Protegida por la carta real, posee independencia editorial, una sólida infraestructura e importantes recursos financieros, pues como es sabido, en su mayoría provienen de un impuesto al consumo de televisores 
y de la venta de sus productos culturales, lo que le permite no depender del gobierno para obtener recursos para su operación.

El caso de Argentina en la región latinoamericana llama la atención por su relativamente nuevo y claro uso de la audiovisualidad serializada como parte de una política pública de intervención gubernamental y con un marco regulatorio específico para la práctica ciudadana en pro de la democracia, así como la promoción de diversos temas sociales (Pía Nicolosi, 2013; Rivero, 2018). Sobre todo, luego de un estancamiento y precarización de la producción de la ficción televisiva en décadas anteriores (Mazzioti, 2006) y siendo pionera en América Latina en introducir la televisión en el continente en 1951 y que ésta fuera pública como parte de la expansión de medios propiciada por el peronismo (Toussaint, 2017).

El elemento clave en el contexto sociopolítico contemporáneo es la implementación de la Ley de Servicios de Comunicación Audiovisual durante el mandato de Cristina Fernández en la década pasada que particularmente ordenó el fortalecimiento de la producción nacional y garantizar el derecho humano a la información y a la libertad de expresión ${ }^{x i i i}$, en el marco de los giros políticos a la izquierda en la región.

\section{Análisis del caso mexicano}

En el caso de México no ha existido una política cultural ni de comunicación del Estado en relación con la ficción audiovisual serializada en su papel en la consolidación de la democracia. El sector audiovisual se ha fortalecido de manera privada y la realización de seriales audiovisuales en televisión ha estado predominantemente orientada hacia el formato de telenovela desde 1958 con la primera producción Senda prohibida, manufacturada por Telesistema Mexicano que años más tarde se fusionaría con Televisión Independiente de México para formar Televisa. Esta telenovela concentró los rasgos definitorios del formato en su origen y desarrollo: fue patrocinada por una empresa, Colgate-Palmolive ${ }^{\mathrm{xiv}}$ (La Pastina, Rego \& Straubhaar, 2004), tuvo una importante influencia del radio, cine y del teatro con guionistas, directores y actores, entrañó intensamente la estética del melodrama, se industrializó el formato, se insertó en el mercado global; sus temáticas oscilaron entre el amor y la preservación de valores tradicionalistas y morales con historias sentimentales, entre otros, conformando el modelo Televisa (Mazzioti, 2006).

Es necesario anotar que desde su surgimiento la televisión en México ha estado estrechamente vinculada al Estado mexicano que se caracterizaba por un autoritarismo extremo a partir de un partido único, el Partido Revolucionario Institucional (PRI), por ejemplo, diversos movimientos sociales y políticos en las décadas de 1960 y 1970 fueron enfrentados con violencia y desapariciones forzadas de manera selectiva. El clima político se caracterizaba por ende a la obediencia al poder y la televisión no era la excepción en virtud de que era el Estado quien otorgaba licencias de operación, se definió una relación de mutua necesidad. De modo que el contexto de producción mediática era definido 
por ello. Incluso se ha llegado a señalar que se favorecía la producción de "televisión para jodidos" que hacía Televisa en el ámbito comercial "buscando la sumisión y control político" (Villamil, 2013) ${ }^{\mathrm{xv}}$, donde el entretenimiento mediático estaría mayormente vinculado al escapismo.

Pese a los trabajos de Miguel Sabido de EE, Televisa se caracterizó por orientar predominantemente sus temáticas a las relaciones de pareja, con un casi total desapego al contexto sociopolítico. En años más recientes la coyuntura de la transición a la democracia le orilló a integrar contenidos de carácter político e ideológico a partir de intereses muy particulares (Orozco \& Franco, 2011). En adelante, este enfoque hacia la telenovela como formato estratégico de la producción audiovisual marcaría los trabajos de la industria en México por muchas décadas ${ }^{\mathrm{xvi}}$, que además la convertiría en el sello de la exportación de productos culturales mexicanos, al grado de ser uno de los principales productores en el mundo.

En suma, la producción de ficción audiovisual serializada mexicana ha pasado por varios momentos importantes en su evolución, sin embargo, resaltan tres que podrían haber incidido de forma importante en la conformación del cómo se estructura en la intensa dinámica actual en el ámbito relativo a la televisión pública en ese tema:

1) La temprana incorporación (1975) de temáticas de carácter prosocial y educativo en telenovelas con el trabajo de Miguel Sabido ${ }^{\mathrm{xvii}}$.

2) La integración abierta de elementos de coyuntura política en la trama de la narrativa serial desde una estética realista y melodramática con el tratamiento de temas como el narcotráfico y la corrupción política en el trabajo de la productora Argos. Su concepción $^{\text {xviii }}$ en 1992 proviene de Epigmenio Ibarra, Carlos Payán Velver, Verónica Velasco y Hernán Vera, los tres primeros periodistas y el último cineasta. $\mathrm{La}$ telenovela Nada personal fue la herramienta para una ruptura del modelo Televisa ${ }^{\text {xix }}$.

3) La interpretación de Canal Once el IPN sobre el mandato de los medios públicos en torno a informar, educar y entretener usando como herramienta clave las teleseries. La primera data de 1999 con Camino a casa, creada y producida por Patricia Arriaga y Gustavo Loza. El público meta fue el infantil. El trabajo de Arriaga ha sido constante en la producción de teleseries en ese canal, sobre todo en las de carácter infantil y más recientemente históricas ${ }^{\mathrm{xx}}$.

El contexto sociopolítico de los últimos dos momentos reseñados muy probablemente es un factor clave en este sentido dado que la cultura política mexicana sufre una transformación luego de los movimientos estudiantiles en 1968 y 1971 y su represión. Comienza entonces el proceso de democratización que cobraría mayores dimensiones a partir de las elecciones de 1988 que estuvieron marcadas por la duda razonable de fraude en el proceso electoral, la emergencia del Ejército Zapatista de Liberación Nacional (EZLN) en 1994 y en ese mismo año los magnicidios del candidato a la presidencia de la República del Partido 
Revolucionario Institucional (PRI), Luis Donaldo Colosio, y Francisco Ruiz Massieu, secretario general del mismo partido. El entonces presidente Carlos Salinas de Gortari desplegó intensas políticas de desregulación de los mercados que impactaron en el sector audiovisual y en especial en el ámbito de los medios públicos ${ }^{\mathrm{xxi}}$, ese sexenio estuvo marcado por un importante descontento social.

La alternancia en el poder paulatinamente se dio paralela a los cambios en términos de cultura política en el país y sin duda un ámbito en que ello repercutió fue en el de la integración de elementos del contexto político mexicano en la producción audiovisual, incorporándose a la nueva etapa de expansión de la serialidad a nivel mundial amplificada por la web 2.0.

El Anuario Estadístico de Cine Mexicano 2017 del Instituto Mexicano de Cinematografía (Imcine) incluyó un capítulo especial destinado a estas producciones y con datos de Nielsen IBOPE México estableció que

En las emisoras públicas la más vista en el 2017 fue mexicana, Juana Inés, con 120,000 telespectadores en promedio por emisión. El segundo lugar también fue para una serie nacional, $X Y$, con 107,000 telespectadores en promedio. Las series se consolidaron en los contenidos de ficción con mayor número de horas programadas, incluso por encima de las telenovelas. Entre el 2013 y el 2017, la transmisión de producciones nacionales en televisión abierta comercial aumentó 8 por ciento (Guerrero, 2018).

\section{Método}

Se realizó un estudio de carácter descriptivo por lo que se llevó a cabo una indagación exploratoria con perspectiva cualitativa, que desde el punto de vista teórico-metodológico empleó un enfoque documental-analítico (Ortiz, 2015), pues se utilizan datos primarios y secundarios, accediendo a fuentes directas como boletines de prensa, noticias publicadas en diferentes medios de comunicación online, páginas web, e información respecto de la producción de ficción audiovisual serializada por parte de televisoras públicas en México; lo cual forma parte de lo que Jensen (2014) denomina documentos de la producción mediática en dominios públicos, pues dice, "hay datos que más que hacerse, se encuentran...con las redes digitales, los datos sobre el uso de los medios están cada vez más al alcance de todos" (p. 440).

En tal sentido, el rastreo tuvo lugar a través de información digital en dos etapas. La primera tuvo como procedimiento abrir la búsqueda por categorías analíticas como Televisión Pública en México, producción de series de televisión, televisoras públicas y ficción audiovisual en la web. Con ello aparecían nombres de series en diversos documentos, los cuales obtenían una búsqueda particular corroborando la existencia del título, así como el año de producción, creador (a), número de capítulos, año y género, en diversos sitios de medios online como (blogs de cine, páginas de prensa, de revistas de diversa índole), de video como YouTube y redes sociales como Facebook y Twitter. 
A partir de todo ello se fue armando un listado del cual se iba rastreando datos específicos de acuerdo con las variables establecidas a fin de obtener la mayor cantidad de detalles posible de cada una, verificando los datos en varias fuentes cruzando la información obtenida e incluso en algunos casos realizando el visionado de las mismas para corroborar datos específicos. Una fuente de información relevante fue el propio sitio de Canal Once, donde la mayoría de las distintas series producidas tienen sus propios enlaces para hacer el visionado de las mismas, así como los boletines oficiales de la televisora respecto del estreno de varias de ellas.

En la segunda etapa se recurrió a los sitios disponibles de las televisoras públicas en México a partir de Toussaint (2009), para identificar en las páginas web de las mismas si alguna televisora consignaba la producción de algún producto cultural en análisis.

La indagación a partir de este método permitió configurar una base de datos, la cual se elaboró teniendo como observables producciones de las que se clasificó: a) Televisora-productora, b) año, c) duración en temporadas y episodios, d) producción institucional sola o en colaboración, así como e) el género y subgénero. El registro y mapeo se desarrolló con base en los siguientes criterios de inclusión:

- Las teleseries producidas y transmitidas por algún sistema de Televisión Pública en México

- Los productos culturales audiovisuales que tuvieran una estructura de serial ${ }^{\text {xxii }}$
- Los productos culturales audiovisuales que tuvieran como formato y subgénero a los dramas en recreaciones ficcionales completas $^{\mathrm{xxiii}}$.

- Se incluyeron los formatos puros de teleserie y telenovela ${ }^{\text {xxiv }}$.

El objetivo de la construcción de la base de datos fue detectar el comportamiento de la ficción audiovisual serializada en la Televisión Pública en México para consecuentemente identificar su dimensión, así como sus oportunidades en el nuevo entorno mediático.

La base de datos aún es preliminar en virtud de que el periodo de recolección fue en enero, febrero y marzo de 202, de que existe poca claridad en la definición de formatos dado que en las últimas décadas se han experimentado diversos procesos de hibridación entre géneros y formatos (Lacalle, 2001) y de que se trata de una industria dinámica.

\section{Resultados}

De la construcción de la base de datos sobresale que la producción de ficción audiovisual serializada que se produce en la Televisión Pública mexicana es escasa, se concentra en la Ciudad de México donde se ubica la sede del Canal Once; la producción regional prácticamente es inexistente y el principal formato han sido las teleseries.

El Canal Once del Instituto Politécnico Nacional es la televisora pública que ha desarrollado esta labor a partir de 1999. Pese a ello llama la atención que el fenómeno llega a México casi setenta

Global Media Journal México, 18(35), 1-31, julio - diciembre 2021. 
años después que en Reino Unido. Esto a pesar de que la televisora mexicana fue la primera de carácter educativo y cultural en América Latina.

Como puede observarse en la Gráfica 1, se identificaron un total de 27 producciones: 26 corresponden a Canal Once (96\%) y una al Sistema Chiapaneco de Radio, Televisión y Cinematografía.

\section{Gráfica 1}

Producciones de ficción audiovisual serializada en TV Pública en México

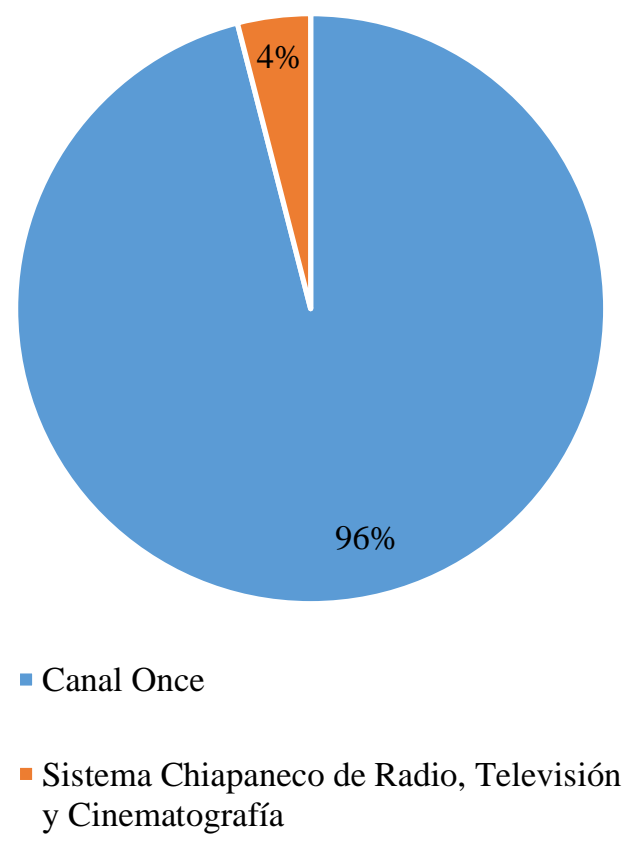

N: 27 títulos

Como puede verse en la Tabla 1, destaca que la producción que nos atañe es sistemática en esa televisora y prolífica pues de 2008 a 2016 se dio de manera ininterrumpida, e incluso hubo años en ese periodo que se lanzaron hasta tres títulos: en 2010 (Soy tu fan, Bienes Raíces y Los Minondo), 2012
(Paramédicos, Kipatla y Pacientes), y en 2015 (Requiem por Leona Vicario, Sofía Luna. Agente especial y Kin) a pesar de las restricciones en materia presupuestarias comunes en los medios de carácter público.

Tomando en cuenta que la producción de ficción audiovisual producida por la televisión pública tiene más de veinte años, la producción de Canal Once es baja, comparada con el volumen de producción de ficción televisiva por parte de Televisa a pesar de la disminución en su producción ${ }^{\mathrm{xxv}}$, pues según datos de Obitel (2020) en 2019 Televisa exhibió 16 títulos nacionales inéditos ${ }^{\mathrm{xxvi}}$.

No obstante, es necesario señalar que se configuró un patrón de producción en este rubro, es decir, la producción sistemática y definida de seriales televisivos de ficción, el cual inició en 1999 con Camino a casa de Canal Once que ha continuado, al menos hasta este registro en 2020. Muy probablemente, esa primera serie marcó la pauta en relación a la definición de un público clave pues nueve de las producciones de Canal Once (33\%) fueron producidas y dirigidas a un público infantil. Durante la primera década de producción (19992008), se manufacturaron seis títulos, destacando en cuatro de ellos la intervención por parte de Patricia Arriaga.

La colaboración con otras instituciones arroja una predominancia de 70\% (19 productoras) frente a $30 \%$ (ocho sólo de Canal Once), lo que contribuye a la diversidad y pluralidad de actores que producen y por ende la pluralidad de voces, así como el estímulo a la producción independiente. 


\section{Tabla 1}

Seriales de ficción de Canal Once

\begin{tabular}{|c|c|c|c|c|}
\hline Año & Título & Temporadas & Género & Productor/Creador \\
\hline 1999 & Camino a casa & 2 temp. 12 capítulos & Infantil. Drama familiar & Gustavo Loza/Patricia Arriaga \\
\hline 2002 & $\begin{array}{l}\text { El Diván de } \\
\text { Valentina }\end{array}$ & 3 temp. 52 capítulos & Infantil. Drama familiar & Patricia Arriaga \\
\hline \multirow{4}{*}{2006} & Futboleros & 2 temp.26 capítulos & Infantil. Drama familiar & Rafael Illescas \\
\hline & Fonda Susilla & 1 temp. 26 capítulos & Infantil. Drama familiar & Prod. Canal 11/Bravo Films \\
\hline & Cuentos de pelos & 1 temp. 13 capítulos & Comedia Infantil & Patricia Arriaga \\
\hline & Línea Nocturna & 1 temp. 13 capítulos & Drama-suspense & $\begin{array}{c}\text { Antonio Pardo/La Fórmula } \\
\text { Secreta }\end{array}$ \\
\hline 2008 & Woki tokis & 1 temp.13 capítulos & $\begin{array}{l}\text { Infantil/Comedia de } \\
\text { situación } \\
\end{array}$ & Alfredo Marrón/Phoenix Films \\
\hline 2009 & $X Y$ & 3 temp. 31 capítulos & Drama & $\begin{array}{c}\text { Patricia Arriaga/Nao } \\
\text { Films/Mysthic Entertainment }\end{array}$ \\
\hline \multirow{3}{*}{2010} & Soy tu fan & 2 temp. 26 capítulos & Comedia romance & $\begin{array}{c}\text { Pablo Cruz y Constanza } \\
\text { Novick/Canana Films } \\
\text { Marcel Ferrer, Alfredo }\end{array}$ \\
\hline & Bienes Raíces & 1 temp. 13 capítulos & Drama & $\begin{array}{c}\text { Marrón/Frame-Maker } \\
\text { Productions }\end{array}$ \\
\hline & Los Minondo & 1 temp. 10 capítulos & Drama histórica de época & $\begin{array}{l}\text { Carlos Bolado/Fernando } \\
\text { Sarinaña/Canana Films }\end{array}$ \\
\hline 2011 & Niño Santo & 2 temp. 14 capítulos & Drama & Pablo Cruz/Canana Films \\
\hline \multirow{3}{*}{2012} & Paramédicos & 3 temp. 35 capítulos & Drama & $\begin{array}{c}\text { Sandra García/Lemon } \\
\text { Estudios }\end{array}$ \\
\hline & Kipatla & 2 temp. 24 capítulos & Drama Infantil & Prod. Canal 11/Conapred \\
\hline & Pacientes & 2 temp. 46 capítulos & Drama & Karina Blanco \\
\hline 2013 & Alguien más & 1 temp. 13 capítulos & Comedia romance & $\begin{array}{c}\text { Constanza Novick/Canana } \\
\text { Films } \\
\end{array}$ \\
\hline 2014 & Crónica de castas & 1 temp. 9 capítulos & Drama & $\begin{array}{l}\text { Jimena Gallardo/Ojo de hacha } \\
\text { producciones }\end{array}$ \\
\hline \multirow{3}{*}{2015} & $\begin{array}{c}\text { Requiem por Leona } \\
\text { Vicario }\end{array}$ & 4 capítulos. Miniserie & Drama histórica de época & Patricia Arriaga/Bravo Films \\
\hline & $\begin{array}{c}\text { Sofia Luna. Agente } \\
\text { especial }\end{array}$ & 1 temp. 13 capítulos & $\begin{array}{l}\text { Divulgación científica. } \\
\text { Infantil }\end{array}$ & Prod. Canal 11 \\
\hline & Kin & 1 temp. 13 capítulos & $\begin{array}{c}\text { Infantil, histórica } \\
\text { contemporánea }\end{array}$ & $\begin{array}{l}\text { Patricia Arriaga/Bravo } \\
\text { Films/Red de Radiodifusoras }\end{array}$ \\
\hline 2016 & Juana Inés & 1 temp. 7 capítulos & Drama histórica de época & Patricia Arriaga/Bravo Films \\
\hline \multirow{4}{*}{2018} & Malinche & $\begin{array}{l}1 \text { temp. } 5 \text { capítulos. } \\
\text { Miniserie }\end{array}$ & Drama histórica de época & Patricia Arriaga/Bravo Films \\
\hline & Niñas promedio & 1 temp. 7 capítulos & Drama & $\begin{array}{c}\text { Ximena Escalante/Nivel Diez } \\
\text { Film+Post }\end{array}$ \\
\hline & Guardia García & $\begin{array}{c}1 \text { temporada, } 5 \text { capítulos. } \\
\text { Miniserie }\end{array}$ & Thriller policiaco & $\begin{array}{c}\text { Javier Solórzano } \\
\text { Casarín/North Films }\end{array}$ \\
\hline & Perros Negros & 2 temp. 5 capítulos & Drama histórica de época & Eduardo Díaz/Lemon Estudios \\
\hline 2020 & Todo por nada & $\begin{array}{c}1 \text { temp. } 5 \text { capítulos. } \\
\text { Miniserie }\end{array}$ & Drama & $\begin{array}{c}\text { Mafer Suárez /Curiosity } \\
\text { Media Group } \\
\end{array}$ \\
\hline
\end{tabular}

Global Media Journal México, 18(35), 1-31, julio - diciembre 2021. 
Asimismo, en términos de pluralidad es relevante el dato que puede identificarse en la Tabla 1, 20 del total de las producciones han sido bajo el esquema de la coproducción, se observó la presencia de 14 instituciones para ello. Las productoras que han colaborado en este proceso han sido principalmente: Bravo Films 19\% (en cinco títulos) y Canana Films 15\% (cuatro títulos). Con menos contribuciones se observó a Lemon Estudios (dos), y el resto como La Fórmula Secreta, Phoenix Films, Nao Films, Mysthic Entertainment, Frame-Maker Productions, Conapred, Ojo de Hacha Producciones, Red de Radiodifusoras, Nivel Diez Film+Post, North Films y Curiosity Media Group, con un título en colaboración. Se observa con ello el estímulo de la televisora a la producción independiente.

La revisión por género y subgénero permitió identificar que han predominado el infantil en un $33 \%$ (nueve) y los históricos-de época en un $22 \%$ (seis) los cuales ocuparon una quinta parte de la producción de la televisora. Esto último puede ser relevante si se considera que la historia nacional forma parte importante de la construcción de la identidad, pero más aún si las recreaciones se orientan a la reflexión de la historia misma y a mostrar versiones distintas de las oficiales. Sobre los géneros también destaca la incursión a subgéneros poco desarrollados en la televisión mexicana como el de suspense y el thriller policiaco, con títulos como Línea nocturna (2006) y Guardia García (2018). Para el caso del público objetivo se pueden mencionar dos producciones dirigidas a adolescentes Soy tu fan (2010) y Niñas promedio (2018).
Finalmente, se pudo distinguir únicamente un título producido por una televisora pública nacional al interior de la república, la telenovela Mucho corazón que fue producida por el Sistema Chiapaneco de Radio, Televisión y Cinematografía en conjunto con PCI Media Impact y el Banco Mundial en 2012.

Lo anterior deja claro que el espacio de producción de ficción audiovisual serializada e incluso unitaria tiene un potencial de desarrollo para la televisión pública en virtud de la importancia que el entretenimiento mediático tiene para la vida social. Según Obitel (2020), el 39\% de las horas transmitidas en televisión abierta en México correspondieron al entretenimiento $^{\text {xxvii }}$. No obstante, aún queda pendiente el anclaje a las preferencias del público pues de acuerdo al mismo estudio, sólo una televisora pública figura entre los canales más vistos en señal abierta, el $6 \%$ de los entrevistados reportó ver el Canal Once.

\section{Conclusiones}

El trabajo anterior ha tratado de analizar el panorama de oportunidad de la producción audiovisual serializada desde y en la televisión pública mexicana, considerando las nuevas lógicas de producción, distribución y consumo de contenidos alteradas por la reconfiguración global del paradigma comunicativo imperante hasta las últimas décadas en virtud de la digitalización y la web 2.0 que propició la convergencia mediática; mismo que se ha

Global Media Journal México, 18(35), 1-31, julio - diciembre 2021. 
vinculado con un declive de la democracia en su modelo representativo dando paso a la democracia de vigilancia (Keane, 2018) que supone un amplio escrutinio de la misma con el potencial auge de la abundancia mediática como fenómeno global.

En ese marco, también se intentó poner en perspectiva la oportunidad de la producción en ese sentido considerando el papel que la televisión pública posee en la democracia a partir de la implementación de diversos valores, así como la búsqueda de un entorno mediático donde haya pluralidad de contenidos, una amplia oferta televisiva, así como el desarrollo de contenidos independientes que den voz a los distintos sectores de la sociedad (Valdés, 2013).

En ese escenario, el papel de los medios públicos, en particular de la Televisión Pública, se observó trascendental pues su naturaleza le dota de atributos para contribuir en los cambios democráticos en el país tendiendo como ventaja la señal abierta frente a la brecha digital para alcanzar a distintos sectores de la población de manera fragmentada, por la televisión tradicional (abierta y aérea) y por el internet según la conectividad por estratos y geográfica.

De modo que, como señala Pía Nicolosi (2013), los cambios en materia tecnológica impliquen dimensiones en lo político, social y cultural a partir de la condición de interactividad, la posibilidad de acceso libre y gratuito desarrollo de la industria nacional y local, la producción independiente el derecho a comunicar, al tiempo que interpelan a la audiencia desde sus propias matrices culturales. Incluso considerando que la propia abundancia mediática y los diversos intereses que juegan en el escenario mundial respecto del capitalismo articulan lógicas como la sobreinformación y desinformación.

Asimismo, el potencial para aportar un mayor conocimiento ciudadano sobre asuntos políticos (Holtz-Bacha \& Norris, 2001) puede predisponer a una mayor receptividad del público con lo que hay mejores oportunidades de hacer una labor prosocial y prodemocrática a través de diversas formas. La ficción audiovisual es un género valioso por su importancia en el entretenimiento, incluso como una tendencia mundial que con el melodrama como elemento central se ha ubicado en diversos momentos de la historia de la humanidad, desde las novelas por entregas o folletines, el teatro, la radio, el cine, la televisión y en la actualidad el internet, sin obviar el papel central que la televisión ha tenido convocando a los medios que le precedieron y luego integrándose y expandiéndose en las nuevas dinámicas de transmisión.

Particularmente, cuando en la actualidad hay un auge global de la serialidad fundamentada en la larga trayectoria del servicio público, en especial el inglés que logró conjuntar la narratividad audiovisual, el contexto sociopolítico y la calidad en la producción; el modelo hollywoodense inicialmente caracterizado por la espectacularidad y luego por diversos procesos como la influencia del cine de autor; la producción serial de calidad en la tv de cable con HBO; así como en industrias audiovisuales como la nórdica, alemana, francesa, turca, y otras, potencializadas por el streaming. Asimismo, observamos también la globalidad de la 
supervivencia del melodrama en la ficción televisiva y su capacidad de adaptación a las nuevas plataformas, pues la relación audienciaentretenimiento mediático no sólo significa o se articula con la degradación cultural propia de la cultura de masas e implica procesos de incivilidad sino también con la festividad, la sátira, la consciencia política dada la heterogeneidad social y contextual de las audiencias.

México no es ajeno a esa tendencia mundial, sobre todo con el confinamiento que la crisis de la COVID-19 impuso al mundo en 2020 y 2021, pues el consumo de diversos productos culturales aumentó y en especial el de las series de ficción. En nuestro país, las bases de la narratividad televisiva las instaló Televisa con su formato estrella de telenovelas y su propio modelo (Mazzioti, 2006), pero la propia realidad mexicana revestida de importantes cambios sociopolíticos alteró ese estándar fundacional en los noventa y la narrativa audiovisual serializada dio un giro en los noventas con el trabajo de Argos y el inicio de la labor de Canal Once en ese ámbito y en la programación infantil, colocándose prácticamente como el único canal público del país que produce narrativas seriales televisivas y que se sitúa, aunque marginalmente comparado con Televisa y luego $\mathrm{Tv}$ Azteca, entre los diez canales más vistos de televisión abierta en los últimos años.

La elaboración de una base de datos en la que se registró el inicio de la producción en 1999 al respecto dejó ver que, excepto el Canal Once y el Sistema Chiapaneco de Radio, Televisión y Cinematografía, el resto de sistemas estatales, federales y universitarios no han producido teleseries de ficción serial. Se identificaron trabajos de docudramas tanto de Canal 22 como de Tv UNAM y el Canal 44, no obstante, se asume que la conjunción ficción y serialidad genera mayor vinculación afectiva con la audiencia y es un ámbito poco aprovechado. El Canal Once parece haber definido una política de producción de contenidos interesada en la ficción audiovisual serializada a partir de la noción de entretenimiento de calidad como eje para cumplir su mandato como medio público de informar, educar y entretener. Ello es relevante si se considera que en México no ha existido alguna política cultural, una acción política del Estado, enfocada a la serialidad televisiva de ficción como el caso argentino e inglés con la BBC. Su producción es abundante comparada con la de los otros sistemas, pero marginal histórica y cuantitativamente hablando. En ese panorama, es posible identificar la oportunidad para la televisión pública y aunque esta propuesta no es del todo innovadora habiendo interesantes trabajos al respecto sobre todo en la región (Becerra et al., 2012; Franco, 2013), esta oportunidad se identifica en la realidad mexicana.

Es claro que ello no resulta una tarea sencilla pues hay que vencer, por un lado, los aspectos estructurales como la desigualdad social que impacta en el acceso a internet con las multipantallas que implica, así como los condicionantes en la apropiación cultural de los bienes simbólicos y productos culturales de esta índole desde diversas competencias.

Para ello, se revisó que el eduentretenimiento ha mostrado ser valioso en distintas experiencias globales y en particular en América 
Latina para promover cambios en el comportamiento en temas como la salud y la pobreza y puede ser útil como herramienta de intervención para procesos democráticos frente a la manipulación y persuasión que la propaganda política o religiosa que históricamente han operado diversos medios de comunicación, muchos de ellos asociados al Estado.

Se analizó que se hace necesario considerar la dimensión individual de la que estamos investidos los sujetos sociales que deriva en procesos psicológicos como el disfrute mediático también vista en su momento como fruición de la que hablaba la Escuela Sociocrítica de Frankfurt pero no necesariamente asociada a la degradación cultural, sino al goce vinculado con aprendizaje social y sus particularidades fundamentadas en la inducción afectiva, la identificación con los personajes, la resonancia personal y la cercanía cultural. Como señala Rincón (en Pía Nicolosi, 2013) es imperativo ganar la atención del público y convertir la televisión en un dispositivo útil para el televidente al contar historias que respondan a las necesidades y expectativas de las audiencias, brinden contexto e información que permitan al televidente actuar en su vida cotidiana, construyan mensajes que promuevan ciudadanos activos en la solución de sus problemas con los recursos que tienen a mano y creen mensajes que respeten su inteligencia y la competencia de ver televisión en la vida colectiva; de modo que, siguiendo a García Canclini (1987), se democratice la cultura y se fomente la democracia participativa.

De hecho, la articulación entre el EE y el disfrute mediático es productiva como se ha registrado en un estudio desarrollado de manera conjunta entre el Observatorio de los Contenidos Audiovisuales (OCA) de la Universidad de Salamanca y el Grupo de Investigaciones en Comunicación y Cultura PBX de la Universidad del Norte (Colombia), pues ha concluido que una mayor identificación con el protagonista del capítulo que vehiculaba el mensaje educativo se asociaba a una mayor elaboración cognitiva, lo que conducía a su vez a actitudes más favorables hacia los temas abordados (Igartúa \& Vega, 2014), sobre todo porque estamos hablando del uso de mensajes integrados a la narración audiovisual. La investigación es relevante porque el éxito de una producción de entretenimiento mediático (una serie, una comedia de situación, un largometraje, una telenovela) depende, en gran medida, de cómo responden las audiencias a los personajes protagonistas (Igartúa \& Muñiz, 2008).

Por lo que asimismo, se hace ineludible ampliar las tareas de investigación académica con ópticas distintas de las tradicionales para entender y analizar las motivaciones personales a la hora de sintonizar el televisor (Franco, 2013), asumiendo al hecho de ver televisión como un proceso amplio y complejo, la televidencia, en la que existen una serie de mediaciones en momentos antes, durante $\mathrm{y}$ después de ver los mensajes en los que se producirá sentido y harán diversas resignificaciones (Orozco, 2014). De modo que puedan observarse sin prejuicios ideológico-científicos: efectos, modos de recepción, de negociación, de apropiación a fin de fortalecer las tareas prosociales y prodemocráticas que la televisión pública promueve y promovería en esta lógica. Eso es relevante si se considera que 
cuando se trata de mensajes particularmente persuasivos como los de la propaganda, la publicidad política o las campañas de promoción de la salud existen diversas metodologías de estudio, no obstante, los valores de la democracia se transmiten de manera inherente en el mensaje, no hay una lógica de persuasión, pero sí podrían observarse efectos incidentales o acumulativos que resulten de interés científico y social. También ello es pertinente en virtud de la ampliación del sistema de medios, de la convergencia mediática, de los procesos de autocomunicación e interacción, de la cultura participativa; es decir, de la complejización de los objetos de estudio con investigación sistemática y abierta a la constatación empírica recuperando los aportes teórico-metodológicos de los distintos enfoques en la investigación de la comunicación.

\section{Referencias bibliográficas}

Austria, X. (2019, April 30). Así fue como Argos conquistó a Netflix con 'Ingobernable' para tener una segunda oportunidad. Entrepreneur. https://www.entrepreneur.com/article/332837

Banco Mundial (2014). Telenovela "Mucho Corazón” sirve como vehículo de educación financiera en México. https://www.bancomundial.org/es/results/2014/09/04/using-a-soap-opera-as-a-vehicle-for-financialeducation-in-mexico

Barthes, N. (2018). El placer de sufrir: un estudio de recepción de las películas de terror. [Bachelor's thesis Universidad de San Andrés]. https://repositorio.udesa.edu.ar/jspui/handle/10908/16581

BBC (2013, August, 5). ¿Puede la televisión ser un anticonceptivo? BBC. https://www.bbc.com/mundo/noticias/2013/08/130805_tecnologia_television_natalidad_anticonceptivod $\mathrm{p}$

Becerra, M., Castillejo, Á., Santamaría O. \& L. Arroyo (2012). Cajas mágicas. El renacimiento de la televisión pública de América Latina. Tecnos.

Becerra, M. \& Waisbord, S. (2015). Principios y “buenas prácticas” para los medios públicos en América Latina. Organización de las Naciones Unidas para la Educación, la Ciencia y la Cultura.

Bouman, M. (1999). Collaboration for Pro-social Change: The Turtle and the Peacock. The EntertainmentEducation Strategy on Television. Netherlands: Thesis Wageningen Agricultural University.

Canal Once (2017). Políticas de Comunicación de la Estación de televisión XEIPN Canal Once del Distrito Federal. https://canalonce.mx/docs/autorregulacion/PoliticasdeComunicacionDG-DPC-08_01.pdf

Carrión, J. (2015). Teleshakespeare. Las series en serio. Tintable/UANL.

Cascajosa, C. (2009). La nueva edad dorada de la televisión norteamericana. Secuencias: Revista de Historia del Cine. 29. 7-31. https://repositorio.uam.es/handle/10486/5701

Global Media Journal México, 18(35), 1-31, julio - diciembre 2021. 
Castells, M. (2009). Comunicación y poder. Siglo XXI.

Cornelio-Marí, E. M. (2020). Melodrama mexicano en la era de Netflix: algoritmos para la proximidad cultural. Comunicación y Sociedad, (00), 1-27. https://doi.org/10.32870/cys.v2020.7481.

De la Torre, T. (2016). Historia de las series. Rocaeditorial.

Dorcé, A. (2005). The politics of melodrama: The historical development of the Mexican telenovela, and the representation of politics in the telenovela Nada Personal in the context of transition to democracy in Mexico. [Doctoral dissertation, Goldsmiths College University of London].

Dorcé, A. (2020). Escenarios emergentes del melodrama en el paisaje audiovisual contemporáneo. Comunicación y Sociedad,(00), 1-18. https://doi.org/10.32870/cys.v2020.7501.

Instituto Federal de Telecomunicaciones (2018). Encuesta Nacional de Consumo de Contenidos Audiovisuales. http://www.ift.org.mx/sites/default/files/contenidogeneral/medios-y-contenidosaudiovisuales/encca18nacional.pdf

Eco, U. (1983). El superhombre de masas. Debolsillo.

Esteinou, J. (2008). ¿Por qué defender los medios de comunicación públicos en México? Razón y Palabra (13). http://www.redalyc.org/articulo.oa?id=199520724014.

Franco, F. (2013). Medios públicos: la audiencia y el nuevo escenario público de comunicación audiovisual ¿Cómo medir esa relación? ¿Por qué tenerla en cuenta?. https://library.fes.de/pdffiles/bueros/uruguay/10762.pdf

García Canclini, N. (1987). Políticas Culturales en América Latina. Editorial Grijalbo.

Gutiérrez, V. (2018, April 11). El fuerte boom de las series que se transmiten en México. El Economista https://www.eleconomista.com.mx/arteseideas/El-fuerte-boom-de-las-series-que-se-transmiten--enMexico-20180411-0150.html

Holtz-Bacha, C. \& Norris, P. (2001). To Entertain, Inform, and Educate: Still the Role of Public Television. Political Communication. 18(2), 123-140. http://dx.doi.org/10.1080/105846001750322943

Igartúa, J.J. (2008). Identificación con los personajes y persuasión incidental a través de la ficción cinematográfica. Escritos de Psicología - Psychological Writings, (2)1, 42-53. https://www.redalyc.org/articulo.oa?id=271020194006

Igartúa, J. J. \& Muñiz, C. (2008). Identificación con los personajes y disfrute ante largometrajes de ficción. Una investigación empírica. $\quad$ Comunicación $\quad y \quad$ Sociedad $\quad$ XXI(1), $\quad 25-52$. https://diarium.usal.es/jigartua/files/2012/07/Igartua-Mu\%c3\%b1iz-CS-2008.pdf

Igartua, J.J. \& Vega, J. (2014). Ficción televisiva, edu-entretenimiento y comunicación para la salud. Revista de Estudios de Juventud, (106), 1-15.

Global Media Journal México, 18(35), 1-31, julio - diciembre 2021. 
Instituto Nacional de Estadística, Geografía e Informática (2020). Estadísticas a propósito del día mundial del internet de mayo $)$ nacionales. https://www.inegi.org.mx/contenidos/saladeprensa/aproposito/2020/eap_internet20.pdf

Jenkins, H. (2008). Convergence culture. La cultura de la convergencia de los medios de comunicación. Paidós. Jenkins, H. (2009). Fans, blogueros y videojuegos. La cultura de la colaboración. Paidos.

Jensen, K.B. (2014). El proceso de investigación cualitativa. In K.B. Jensen (Ed.), La comunicación y los medios. Metodologías de investigación cualitativa y cuantitativa. FCE.

Karbaum G. (2018). Narrativas social media y el prosumidor mediático. Correspondencias \& Análisis, (8), 219238. https://doi.org/ 10.24265/cian.2018.n8.11

Keane, J. (2018). Vida y muerte de la democracia. FCE.

La Pastina, A. C., Rego, C., \& Straubhaar, J. (2004). La centralidad de las telenovelas en la vida cotidiana de América Latina: Tendencias pasadas, conocimiento actual e investigación por venir. Global Media Journal México, 1(1). https://www.redalyc.org/articulo.oa?id=68710109

Lacalle, C. (2001). El espectador televisivo: Los programas de entretenimiento. Gedisa.

Leanza, D. \& L. Zafarroni (2017). ¿Ves telenovelas? En Latinoamérica han cambiado la vida de miles de personas. Banco Mundial. https://www.bancomundial.org/es/news/feature/2017/01/25/ves-telenovelas-enlatinoamerica-han-cambiado-la-vida-de-miles-de-personas

López, Z. (2021, September 2). Netflix-Televisa: ¿Quién tiene el liderazgo en la producción de series?. Expansión. https://expansion.mx/empresas/2021/09/02/netflix-televisa-liderazgo-produccion-series

Martínez de Rituerto, R. (1989, April 15). Marmaduke Hussey: "La televisión pública sólo es responsable ante el telespectador". El País. https: https://elpais.com/diario/1989/04/16/sociedad/608680807_850215.html

Mattelart, A. (1995). La Invención de la comunicación. Siglo XXI.

Mazzioti, N. (2001). Los géneros en la televisión pública. In O. Rincón (Ed.), Televisión Pública. Del consumidor al ciudadano (pp. 179-207). Convenio Andrés Bello.

Mazzioti, N. (2006). Telenovela, industria y prácticas sociales. Norma.

Morley, D. (1996). Televisión, audiencias y estudios culturales. Amorrortu.

Morley, D. (2009). Medios, modernidad y tecnología. Gedisa.

McBride, S. (1980). Un solo mundo, voces múltiples. FCE

Monge, Y. (2020, April 21). Netflix suma casi 16 millones de nuevos usuarios durante la pandemia. El País. https://elpais.com/economia/2020-04-21/netflix-suma-casi-16-millones-de-nuevos-usuarios-durante-lapandemia.html

Observatorio Iberoamericano de Ficción Televisiva (2020). El melodrama en tiempos del streaming. http://www.obitel.net/wp-content/uploads/2020/11/PT-ES-OBITEL-2020.pdf.

Global Media Journal México, 18(35), 1-31, julio - diciembre 2021. 
Ojea, M.V. (2020, November 17). Internet, tan esencial como el agua y la luz, en la era de la pandemia. El País. https://elpais.com/america/economia/termometro-social-de-america/2020-11-18/internet-tan-esencialcomo-el-agua-y-la-luz-en-la-era-de-la-pandemia.html

Orozco, G. (2005). Desordenamientos educativos comunican a una audiencia que quiera y pueda estar enterada. In Red Nacional de Radiodifusoras y Televisoras Educativas y Culturales (Ed.), Democracia y Medios Públicos. Red Nacional de Radiodifusoras y Televisoras Educativas y Culturales.

Orozco, G. (2014). Televidencias. Comunicación, educación y ciudadanía. UdG.

Orozco, G. \& Franco, D. (2011). Entre espectáculo, mercado y política: La telenovela mexicana en más de cinco décadas. In A. Cueva, C. Estrada, A. Garnica, R. Jara, H. López, G. Orozco, \& S. Soto (Ed.), Telenovelas en México. Nuestras íntimas extrañas (pp. 181-218). Grupo Delphi.

Ortega P. (2005). Medios públicos y Democracia. In Red Nacional de Radiodifusoras y Televisoras Educativas y Culturales (Ed.), Democracia y Medios Públicos. Red Nacional de Radiodifusoras y Televisoras Educativas y Culturales.

Ortega P. (2006). La otra televisión. Por qué no tenemos televisión pública. Red Nacional de Radiodifusoras y Televisoras Educativas y Culturales- UAM-X.

Ortiz, A. (2015). Enfoques y métodos de investigación en las ciencias sociales y humanas. Ediciones de la U.

Ortiz, M. (2018). Producción y realización en medios audiovisuales. RUA-Universidad de Alicante.

Pareja, N. (2009). Entretenimiento de calidad y una dieta balanceada, claves del modelo de televisión de servicio público en México: El caso de Canal Once. Revista Mexicana de Ciencias Políticas y Sociales, 51(206), 119-136. http://dx.doi.org/10.22201/fcpys.2448492xe.2009.206.41037

Pareja N. (2011). Concepciones del servicio público de la televisión en México. Una aproximación desde el 'ser' al 'deber' ser en los sistemas estatales. En Toussaint, F. (coord.), Desafíos y perspectivas de la televisión pública. México: UNAM-SITESA.

Pía Nicolosi, A. (2013). Democratización de la ficción televisiva argentina: hacia una resignificación de la tv pública. Razón y Palabra, (82). https://www.redalyc.org/articulo.oa?id=1995/199525737007

Postman, N. (2012). Divertirse hasta morir. Ediciones La Tempestad.

Richeri, G. (1993). La transición de la televisión. Bosch.

Rivero, E. (2018). La ficción televisiva en Argentina: el fomento estatal y la crisis de la producción privada (20112016). Comunicación y Medios, 27(37), 168-183. https://doi.org/10.5354/0719-1529.2018.48288.

Sartori, G. (1993). ¿Qué es la democracia?. México: TFE-IFE.

Scolari, C. (2008). Hipermediaciones. Elementos para una teoría de la comunicación digital interactiva. Gedisa.

Silverstone, R. (1996). Televisión y vida cotidiana. Amorrortu.

Tocqueville, A. (1957). La democracia en América. México: FCE.

Touraine, A. (1995). ¿Qué es la democracia?. México: FCE.

Global Media Journal México, 18(35), 1-31, julio - diciembre 2021. 
Toussaint, F. (2009). Historia y políticas de televisión pública en México. Revista Mexicana de Ciencias Políticas y Sociales, 51(206), 105-118. http://dx.doi.org/10.22201/fcpys.2448492xe.2009.206.41036

Toussaint, F. (2011). Desafíos y perspectivas de la televisión pública. México: UNAM-SITESA.

Toussaint, F. (2017). Televisión pública en América Latina: su transición a la era digital. Revista Mexicana de Ciencias Políticas y Sociales, (62)229, 223-242. http://dx.doi.org/10.1016/S0185-1918(17)30009-0

Tufte, T. (2004). Eduentretenimiento en la comunicación para el VIH/SIDA más allá del mercadeo, hacia el $\begin{array}{lllll}\text { empoderamiento. } \quad \text { Investigación } & \text { \& }\end{array}$ (12)1, Desarrollo. https://www.redalyc.org/articulo.oa?id=26800102

Valdés Latapí, R. (2013). Modelo de televisión pública como instrumento democratizador en México [Master’s thesis, Instituto Tecnológico y de Estudios Superiores de Monterrey]. Repositorio Institucional. https://repositorio.tec.mx/ortec/bitstream/handle/11285/628907/33068001113198.pdf?sequence=1\&isAll owed=y

Van Dijk, J. (2016). La cultura de la conectividad. Una historia crítica de las redes sociales. Siglo XXI.

Villamil, J. (2013, March 19). Televisión para jodidos. Proceso. https://www.proceso.com.mx/opinion/2013/3/19/television-para-jodidos-115883.html

Vorderer, P. (2003). Entertaiment theory. In J. Bryant, D. Roskos-Ewoldsen y J.R. Cantor (Eds.). Communication and emotion. Essays in honor of Dolf Zillmann. Lawrence Erlbaum Associates.

Williams, R. (1974). Televisión. Tecnología y forma cultural. Paidós.

\section{Notas}

${ }^{\text {i }}$ El presidente de la British Broadcasting Corporation (BBC) en 1989, Marmaduke Hussey declaró que esa televisora, considerada como modelo de independencia y de calidad, ha enfrentado a lo largo de toda su historia el desafío de superar las presiones políticas. (Martínez de Rituerto, 1989).

ii Sin duda se hace necesario relativizar lo que pudiera parecer una perspectiva demasiado optimista en torno a la naturaleza de los cambios tecnológicos actuales. Hay que decir que no puede soslayarse primero, la importancia de la conectividad posible actual con la interactividad que permite la web 2.0 especialmente si ello se compara con la relación medios-audiencia caracterizada por no admitir ningún tipo de interacción, era vertical y cerrada, las llamadas telefónicas o cartas al editor podrían ser insignificantes, no había interacción alguna. La socialidad mediada (Van Dijk, 2016), ha obligado a las grandes corporaciones productoras de contenido a poner más atención a las audiencias pues sus relaciones online organizadas en torno a fandoms (grupos de fans) y sus prácticas transmediales por ejemplo, cuestiona producciones, estructuras, tramas o finales de ficción, así como la mayor visibilidad y escrutinio del ejercicio público. Y tercero, no se puede obviar tampoco que la arquitectura y estructura del mercado intrínseco en los procesos online, controla y condiciona la oferta de contenidos y comercializa datos privados (Van Dijk, 2016) como saliera a la luz a partir del tema de Cambridge Analytica en las elecciones norteamericanas del 2018. Sin duda, un tema amplio y complejo que amerita una discusión más amplia, pero que excede los objetivos de este trabajo.

iii Es decir, las televisoras públicas deben complacer a los gobiernos en turno al tiempo que tratan de cumplir su mandato de educar e informar con objetividad, como lo han declarado directivos de sistemas estatales y federales (Pareja, 2011).

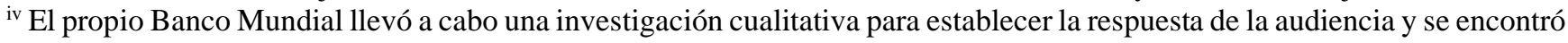
que hubo un aprendizaje respecto de temas financieros y que éste había sido importante, el mismo fue valorado desde el agrado a partir de la integración de contenidos sobre el ahorro a partir de la identificación, aunque hubo diferencias de

Global Media Journal México, 18(35), 1-31, julio - diciembre 2021. 
percepción en Oaxaca y Querétaro. No obstante, según el informe, en general se evaluó como "una ventaja para la telenovela, algo útil y novedoso en un programa de entretención. En particular, estimaron que los diálogos sobre el ahorro eran positivos" (Banco Mundial, 2014).

${ }^{\vee}$ En Argentina se empleó como herramienta de intervención la telenovela Vidas robadas, la cual estuvo inspirada en un caso real, se buscaba concientizar sobre la trata de personas. Para realizarla, los autores contaron con la asesoría de diversas instituciones expertas en el tema para poder abordarla de manera respetuosa. La historia se desarrollaba en el marco del secuestro de personas que eran obligadas a ejercer la prostitución (Leanza \& Zafarroni, 2017).

vi Cabría sin duda una argumentación mayor, con análisis más amplio, no obstante, ello excede las posibilidades espaciales del presente texto.

vii Más del 50\% de los hogares en América Latina y el Caribe no tiene internet de banda ancha. En una de las regiones más golpeadas por la covid-19, eso implica no tener acceso a educación, trabajo o servicios financieros. Las últimas cifras del Banco Mundial muestran que los suscriptores al servicio de banda ancha móvil eran bajos (53\%) y la penetración de la banda ancha fija en los hogares era solo del 46\% (Ojea, 2020).

En México, de acuerdo con la ENDUTIH, 80.6 millones de las personas de seis años o más en el país, hacen uso de Internet (70.1\% de la población), proporción superior a la registrada en 2018 (65.8\%) (INEGI, 2020).

viii En los últimos años diversos festivales mundiales tradicionalmente destinados a premiar y promover la ficción cinematográfica han incluido categorías vinculadas a la ficción serializada en televisión por internet. En México por primera vez el Anuario Estadístico de Cine Mexicano 2017 del Instituto Mexicano de Cinematografía (Imcine) incluyó un capítulo especial destinado a estas producciones (Gutiérrez, 2018).

ix Tiene un énfasis en teleseries pues el comportamiento a nivel global de éstas parece mostrar mejor el pulso del consumo del melodrama.

${ }^{x}$ Si bien, la estructuración de los años puede ser un tanto arbitraria e imprecisa, trata de organizar la temporalidad para un acercamiento más amplio y esquemático, se ha hecho con base en Cornelio-Marí, (2020), De la Torre (2016), Eco (1983), Jenkins (2008, 2009), Karbaum (2018), Lacalle (2001), Postman (1984), Richeri (1993) y Silverstone (1994).

${ }^{x i}$ Posee dominancia en el mercado de OTT en México y a nivel mundial, según el periódico El País en el contexto de pandemia alcanzó alrededor de 190 millones de usuarios en el mundo hasta abril de 2020 (Monge, 2020). En 2013 produce su primera serie (House of cards) y ello cambiaría las reglas de la industria audiovisual tanto en cine como en televisión, estimulando la competencia en la generación de contenidos tanto por el impacto que tuvo la serie, como por modificar las cadenas de producción y distribución al innovar el panorama mediático, pasando de ser reproductor de series hechas para televisión años anteriores, a producir y/o crear, así como por distribuir en un canal nuevo (la web) y extendiendo el consumo desde el televisor a diversos dispositivos: móviles y digitales.

xii Luego vendrían otros proveedores que buscarían seguir ese modelo de negocio como Apple, Amazon Prime, Hulu, HBO Go, Disney +, Starzplay, Yahoo!, Facebook, éstas dos redes sociales sin buenos resultados.

xiii La Secretaría de Medios y Comunicación Pública implementó Contar como una plataforma OTT de video on line y televisión en vivo para acceder al catálogo de contenidos originales de ficciones, documentales, musicales, deportivos y eventos en vivo, así como la programación en vivo de las señales educativas Encuentro, Paka Paka, DXTV, y de la Televisión Pública, CINEAR, Mirador TV y otras señales pertenecientes a la Televisión Digital Abierta. También permite el acceso a los contenidos producidos por el BACUA (Banco de contenidos universales argentinos) y eventos culturales realizados en el CCK (Centro Cultural Kirchner).

xiv Como en los orígenes modernos occidentales e industrializados de las soap operas norteamericanas.

${ }^{x v}$ Jenaro Villamil (2013) da cuenta de las declaraciones en 1993 de Emilio Azcárraga Milmo dueño de Televisa: "Nuestro mercado en este país es muy claro: la clase media popular. La clase exquisita, muy respetable, puede leer libros o Proceso para ver qué dicen de Televisa... Estos pueden hacer muchas cosas que los diviertan, pero la clase modesta, que es una clase fabulosa y digna, no tiene otra manera de vivir o de tener acceso a la distracción más que la televisión", agregó Azcárraga". Villamil señala que "el Tigre quitaba los velos de la retórica y confesaba lo que todo mundo sabía en este país y nadie se atrevía a decirlo: la televisión comercial es para enajenar (“divertir") a los jodidos".

xvi Ver la amplia revisión de Orozco \& Franco (2011).

xvii Dramaturgo, poeta y productor formado en filosofía en la Universidad Nacional Autónoma de México. Produjo en total 7 títulos en este rubro, pero las primeras que conformaron una popular trilogía y paradigma en varios países fueron Ven conmigo, Acompáñame y Vamos juntos. Su trabajo fue pionero en América Latina, así como en países como la India y otros en África. Se considera la primera generación de EE (Tufte, 2004).

xviii La idea básica fue "expandir el periodismo contando historias también desde la ficción". La telenovela Nada personal tenía como proyecto antecedente una teleserie de 13 capítulos sobre asuntos criminales. Esa fue la propuesta a Ricardo Salinas Pliego, dueño de TV Azteca, pero éste sugirió el formato de telenovela de 120 episodios, que costaba lo mismo. Así desarrollaron Nada Personal, después vino Mirada de Mujer (1997) y Se vale soñar (1995). Con estas producciones la televisora alcanzó más de 50\% del share y rompió el monopolio de Televisa (Austria, 2019).

Global Media Journal México, 18(35), 1-31, julio - diciembre 2021. 
xix Para un análisis más profundo ver Dorcé (2005).

${ }^{x x}$ En las Políticas de Comunicación de la Estación de televisión XEIPN Canal Once del Distrito Federal (2017) se enfatiza la identificación directa con el receptor; la producción, coproducción y adquisición de contenidos con eficiencia y calidad, lo cual se observó empíricamente en un estudio censal en 2007 y 2008 a las 31 televisoras públicas del país (Toussaint, 2009) en el que en ese momento su porcentaje de programación propia era importante (60\%) y su programación era retransmitida por varios sistemas en el país. Así como la interacción permanente con la audiencia a partir del defensor de la audiencia, redes sociales e investigación cuantitativa y cualitativa. Destaca también su noción de entretenimiento de calidad identificado reiteradamente en distintos ámbitos (Pareja 2009).

xxi Ver Toussaint (2009).

xxii A fin de evitar ambigüedad en el estudio y la vinculación sistemática con la audiencia que supone la serialidad, preliminarmente debieron dejarse fuera producciones unitarias como Carlota de Habsburgo (Canal Once-2015), Hernán Cortés, Un hombre entre Dios y el diablo (TV UNAM/Fundación Miguel Aleman/SPR/ Fund. UNAM/Canal 44-2018), Maximiliano de México, sueños de poder (TV UNAM/ORF AUSTRIA-2018), Malitzin, la historia de un enigma (TV UNAM/SPR/Fund. Miguel Alemán/Fund. UNAM/AMX Contenidos/Claro Video-2019), Entre dos mundos, la historia de Gonzalo Guerrero (TV UNAM/SPR/Fund. Miguel Alemán/Fundación UNAM/ Canal 44-2019), Hernán Cortés, un hombre entre Dios y el diablo, (TV UNAM/SPR/Fund. Miguel Alemán/Fundación UNAM/ Canal 44-2019) y Ni una menos, ni una sola (Canal 44 UdG-2021).

xxiii No se consideraron los docudramas que son obras que integran información y hechos reales de manera formalizada con técnicas dramáticas, sino solo obras de ficción.

xxiv El registro se ha hecho con base en Mazzioti (2001) para la definición de los mismos.

${ }^{x x v}$ En 2014, el 34\% de las producciones de series estaban a cargo de Televisa, seguida de Argos con el 17\%. Un año antes, el dominio se concentraba entre la compañía de Emilio Azcárraga y Canal Once, con 24\% del mercado de producción cada una (López, 2021).

${ }^{\text {xxvi }}$ El Anuario Estadístico del IMCINE por su parte registró que durante 2020 se produjeron treinta y seis series audiovisuales en México de las cuales Netflix fue la empresa que más creó con catorce historias y Televisa nueve (López, 2021).

xxvii La Encuesta Nacional de Consumo de Contenidos Audiovisuales (2018) registra que el 93\% de los hogares cuenta con televisión, cerca de 51\% de los hogares con televisor mencionaron contar únicamente con señal de televisión abierta. El 72\% de los entrevistados señalaron ver contenidos de canales de televisión abierta y en lo relativo a internet, ese estudio da cuenta de que $64 \%$ de los entrevistados declararon utilizarlo, el $46 \%$ de los entrevistados expresaron consumir contenidos audiovisuales por internet y $89 \%$ de los encuestados que consumen contenidos por internet, lo hacen en su hogar.

Global Media Journal México, 18(35), 1-31, julio - diciembre 2021. 